\title{
Cost-Utility and Budget Impact Analysis for Stopping the Inappropriate Use of Proton Pump Inhibitors After Cessation of NSAID or Low-Dose Acetylsalicylic Acid Treatment
}

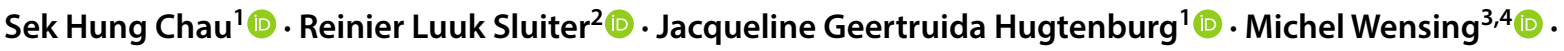 \\ Wietske Kievit ${ }^{2}$ (D) Martina Teichert ${ }^{5}$ (I)
}

Published online: 27 September 2019

(c) The Author(s) 2019

\begin{abstract}
Background In accordance with current guidelines, proton pump inhibitors (PPIs) are now generally prescribed as a protective co-medication in patients taking non-steroidal anti-inflammatory drugs (NSAIDs) or low-dose acetylsalicylic acid (LDASA). However, less attention is paid to the corresponding discontinuation of a PPI after cessation of NSAID or LDASA treatment.

Objective The aim of this study was to assess the extent of inappropriate PPI use, as the proportion of patients who started a PPI as a protective co-medication but continued using these drugs after cessation of NSAID and LDASA treatment. We also sought to estimate the potential cost savings and effect gains of discontinuing inappropriate PPI use and the resulting decrease in adverse effects and their detrimental consequences.

Methods Pharmacy dispensing data were used to map inappropriate PPI use in 2014 for community-dwelling patients. Strategies with or without PPI continuation were compared in the cost-utility analysis for a time horizon of 5 years from a healthcare perspective. Subsequently, incremental costs and effects (quality-adjusted life-years) were estimated with a Markov model.

Results Related to NSAID and LDASA treatment, $11.0 \%$ and 5\%, respectively, of the PPI users were found to inappropriately continue PPI co-treatment. Discontinuation in 71- to 80-year-old patients suggested cost savings of $€ 170.46$ (95\% confidence interval 75-282) at a 0.003 (95\% confidence interval 0.001-0.005) quality-adjusted life-year increase. The total budget impact of stopping inappropriate PPI use related to NSAID/LDASA treatment in the Netherlands would amount to almost $€ 1,050,000$ after 1 year. Correspondingly, successful interventions to stop a patient's inappropriate use would cost up to $€ 29$ and probably would pay for themselves in the following years.

Conclusions A substantial number of patients inappropriately continue to use a PPI after cessation of NSAID or LDASA treatment. Because adverse effects and their detrimental consequences are avoided, interventions to stop inappropriate PPI use, particularly in older patients, are likely to pay for themselves.
\end{abstract}

Parts of this research have been presented during the PCNE 2017 Working Conference in Bled, Slovenia.

Sek Hung Chau and Reinier Luuk Sluiter contributed equally to this work.

Electronic supplementary material The online version of this article (https://doi.org/10.1007/s40266-019-00713-5) contains supplementary material, which is available to authorized users.

Sek Hung Chau

s.chau@amsterdamumc.nl

Extended author information available on the last page of the article

\section{Introduction}

Non-steroidal anti-inflammatory drugs (NSAIDs) and lowdose acetylsalicylic acid (LDASA) may cause serious gastrointestinal (GI) adverse effects such as dyspepsia, peptic ulcers, peptic bleeding and ulcer perforations [1,2]. The use of these drugs substantially contributes to the number of potentially preventable, drug-related hospital admissions $[3,4]$. Proton pump inhibitors (PPIs) effectively prevent GI complications in NSAID and LDASA users [5, 6]. Consequently, PPIs are recommended as a protective co-medication in patients at risk of GI damage during NSAID or LDASA treatment [5-9]. In the Netherlands, since 2012, 


\section{Key Points}

Continued use of a proton pump inhibitor (PPI), started as a protective co-medication to non-steroidal antiinflammatory drug (NSAID) and low-dose acetylsalicylic acid (LDASA) treatment, is substantial. $11.0 \%$ of PPI use continued after NSAID cessation, 5\% of PPI use continued after LDASA cessation.

Inappropriate use of a PPI co-medication was highest in the older age categories.

Interventions to stop inappropriate PPI use easily pay for themselves as they prevent the occurrence of unnecessary PPI adverse effects.

PPIs have been recommended for all patients using NSAIDs aged 70 years and older and for those using LDASA aged 80 years and older. For patients using NSAIDs aged 60 years and older, and LDASA users aged 70 years and older, PPIs are recommended in combination with GI risk-increasing co-medication or co-morbidity [9]. This policy was supported by the development of quality indicators for general practitioners and community pharmacists $[10,11]$.

Incorporated in the prescribing and dispensing process, these quality indicators measure the proportion of patients with a protective co-medication in NSAID or LDASA users at increased GI risk. Over the years in the Netherlands, the concomitant use of PPIs in (older) patients prescribed NSAIDs and LDASA has considerably increased. In NSAID users at risk of GI adverse effects, PPI use increased from $55 \%$ in 1996 [12] to $85 \%$ in 2012; the proportion of susceptible LDASA users with a PPI co-medication grew from $8 \%$ in 2000 to $31 \%$ in 2012 [10]. In 2013, 2.75 million people in the Netherlands (17\% of the total population) used PPIs with on average 235 daily defined doses [13]. In 2015, the PPI omeprazole was the most frequently dispensed drug in the Netherlands with $5.2 \%$ of all drugs dispensed [14].

Although PPIs effectively reduce upper GI damage in patients at risk [7, 15], a number of concerns have been raised concerning their safety [16]. In several studies, PPIs were shown to modestly increase the risk of bone fractures (hip, wrist and vertebrae) in long-term users [17-21]. Furthermore, there is some evidence that PPIs increase the risk of community-acquired pneumonia (CAP), especially shortly after initiation of treatment [22-25].

Finally, there is a consensus that PPI use without a disease or medication-based indication should be avoided [26]. This inappropriate PPI use has been described before [27-31]. The cost effectiveness to add a protective PPI comedication to NSAID or LDASA treatment in patients with an increased risk of GI damage has been well demonstrated [32-34]. However, insight into the potential cost savings and benefits from the discontinuation of inappropriate PPI use following cessation of NSAID or LDASA treatment is lacking.

Consequently, the present study aimed to, first, document the extent of inappropriate PPI use initially related to NSAID and LDASA treatment in the Netherlands. Second, to assess the benefits of the strategy to stop inappropriate PPI use in former NSAID and LDASA users at risk of GI adverse effects as compared to no intervention using a Markov model. A budget impact analysis (BIA) was performed for the potential cost savings resulting from the successful use of interventions to prevent inappropriate PPI use.

\section{Methods}

\subsection{Inappropriate Proton Pump Inhibitor Use}

Routinely collected dispensing data were extracted from the Dutch Foundation of Pharmaceutical Statistics database. The Dutch Foundation of Pharmaceutical Statistics collects dispensing data from more than $95 \%$ of the 1979 Dutch community pharmacies [35]. The database provides detailed information on drugs dispensed including the codes from the Anatomic Therapeutic Chemical code system [36], the prescribed daily dose and the amount dispensed. As a consequence, drug use periods can be calculated by dividing the amount dispensed by the prescribed daily dose. Information on patients' sex and year of birth were also available. Medication of a specific patient was tracked within a pharmacy over time by a defined unique anonymous code per patient. For the present study, data from Dutch community pharmacies were used, which had provided complete data for the years 2013-2014. With these data, the proportions of inappropriate PPI continuation were calculated for the year 2014 in PPI users who started this protective co-medication in addition to NSAID or LDASA treatment but continued to use a PPI after cessation of their potentially harmful medication. Data on 2013 were necessary to establish that PPIs were started in 2014 and thereby not used in the year preceding 2014. The study was approved by the Dutch Foundation of Pharmaceutical Statistics advisory board.

\subsection{Measures}

Patients aged older than 50 years with PPI initiation in 2014 and an NSAID or LDASA treatment period within 10 days before or after PPI dispensing were selected from the database. This selection aimed to select only those PPI users who started using a PPI as a gastroprotective co-medication. 
Patient selection included patients from the age categories for which the guidelines recommend gastroprotection [9, 37]. Younger age categories were also selected for a broader examination of PPI co-treatment initiation and cessation. Subjects with inappropriate PPI use were those with a repeat PPI dispensing and without an NSAID or LDASA treatment period within 10 days before or after this dispensing in the year 2014. Treatment periods were calculated from the amount dispensed divided by the prescribed daily dosage. Thus, NSAID or LDASA use could be taken into account from earlier dispenses. Percentages of inappropriate PPI use were calculated relative to patients who started these drugs as a protective co-medication to NSAID or LDASA treatment.

Current guidelines recommend the initiation of PPI cotreatment in patients aged 60 years and older with NSAID or LDASA use who have additional risk factors for GI damage. Additional risk factors are comorbidity such as rheumatoid arthritis, diabetes mellitus, or heart failure, or co-medications such as selective serotonin reuptake inhibitors or oral corticosteroids [9]. Because the guidelines differentiate between the need to prescribe a protective PPI in patients using an NSAID or LDASA for the age categories between 60-69 years, 70-79 years, and for LDASA also users aged 80 years and older, the results were stratified for these age categories as well as for the 50-59 years age category. Descriptive analyses on frequencies were performed with IBM SPSS Statistics 20 and Microsoft Excel 2007.

\subsection{Cost-Utility Analysis}

Costs were compared for the effectiveness in terms of costs and quality of life in separate models for PPI use during treatment with NSAIDs and with LDASA by two strategies each: (1) PPI use discontinued together with the cessation of the NSAID or LDASA treatment, and (2) PPI use continued after cessation of NSAID or LDASA treatment. For this purpose, Markov models with a time horizon of 5 years were created using Microsoft Excel 2007. The analysis were performed from a healthcare perspective. In view of the age categories involved, costs for productivity losses were less relevant and were not included in the models. The general structure of the models is shown in Fig. 1. Each patient started in a health state affected only by a disorder requiring NSAID or LDASA treatment. After 3-month cycles, patients could transfer to one of the following states: hip fracture, CAP, GI bleeding, death or remain in the initial health state.

Population-based incidence rates of hip fractures, CAP, GI bleeding and death were collected from Dutch Statistics. For the PPI discontinuation strategy, incidence rates were transformed into probabilities and used in this strategy $[38,39]$. For the continuation strategy, incidence rates were transformed into health-state-specific probabilities by using
PPI risk ratios on these events (see Electronic Supplementary Material [ESM]). The different probabilities were constructed in a manner to increase a subject's risk to develop certain events with higher age.

Costs related to GI bleeding were taken from De Groot et al. [32] Costs related to CAP were derived from Spoorenberg et al. [40] and costs for a hip fracture were taken from the Dutch Organisation Veiligheid.nl, which collects information on safety problems in the Netherlands [41]. All costs were updated to 2015 prices by using Dutch consumer price indices [42]. A list for the costs and utilities is given in the ESM.

Utilities for the different health states were collected from the literature. The utilities of hip fractures were based on a systematic review of Peasgood et al. [43]. Utilities for GI bleeding were collected from De Groot et al. for NSAID and LDASA use, respectively $[32,33]$. Because no utility for CAP was available from the literature, a utility was constructed based upon the comparison of the severity of this health state to the other health states used in this study. With these utilities, quality-adjusted life-years (QALYs) were calculated for each scenario. As recommended by the Dutch guidelines for pharmacoeconomic evaluations, costs were discounted at an annual rate of $4 \%$, whereas utilities were discounted at an annual rate of $1.5 \%$ [44].

Parameter uncertainties were taken into account by performing probabilistic sensitivity analyses with Monte Carlo simulations based on 5000 iterations. For each iteration, a random value for each parameter was taken, based on the parameter distribution [38]. These distributions were based upon the $95 \%$ confidence intervals of each parameter. Beta

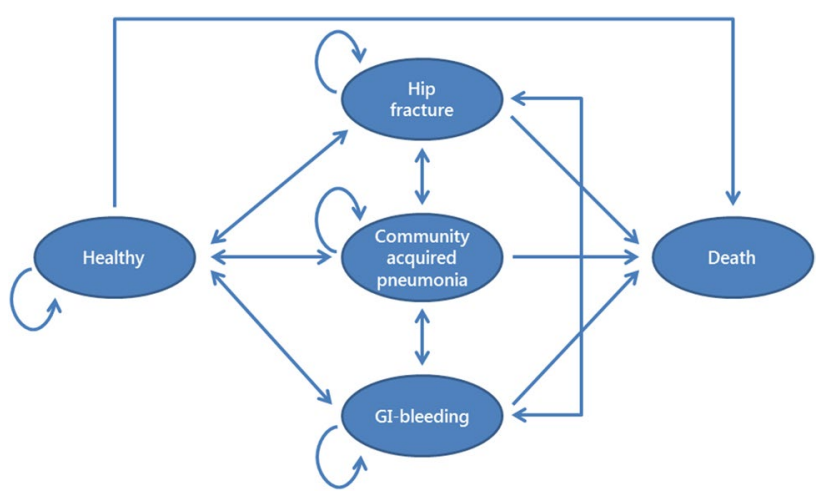

Fig. 1 Markov model for the development of adverse effects resulting from inappropriate use of proton pump inhibitors (PPIs). Subjects started as 'healthy', a health state affected only by a disorder requiring non-steroidal anti-inflammatory drug (NSAID) or low-dose acetylsalicylic acid (LDASA) treatment. Subsequently they could transfer to a state of hip fracture, community acquired pneumonia, gastrointestinal (GI) bleeding or death, or remain in the initial health state. In a following 3-month cycle, patients could stay in the same health state or move to one of the other health states or death. GIbleeding gastrointestinal bleeding 
distributions were used for utilities and probabilities, gamma distributions for costs, and lognormal distributions for risk ratios [39]. With the outcomes of the Monte Carlo simulations, a scatter plot of the incremental cost-effectiveness ratios and a cost-effectiveness acceptability curve were calculated. Seventy-year-old patients served as base cases, as this was the average age of NSAID and LDASA users for whom the use of a protective PPI medication is recommended. The analyses had a time horizon of 5 years. The model was based on NSAID or LDASA use for 5 years at an adherence rate of $68 \%$ [45].

\subsection{Budget Impact Analyses}

A BIA was performed for the potential cost savings of a successful intervention to prevent inappropriate PPI use according to international guidelines [44, 46]. The budget impact was calculated for the first year after stopping from a healthcare perspective. First, the costs of both strategies for stopping and continuation of PPI co-treatment were calculated with the model. The difference in costs between the two strategies were then multiplied with the number of patients who were dispensed a PPI repeat prescription without concomitant NSAID or LDASA use. For the BIA, age categories were chosen corresponding to the cost-utility analysis because different healthcare resources are used with increasing age. The total sum of the different age categories was considered as the total budget impact for ceasing inappropriate PPI use after 1 year.

\section{Results}

\subsection{Extent of Inappropriate Proton Pump Inhibitor Use}

In 2014, the numbers of NSAID and LDASA users dispensed a PPI within 10 days of a period of NSAID or LDASA use amounted to 247,460 and 173,852 , respectively (Table 1). Overall, $11.0 \%$ of the PPI users who started a PPI in combination with an NSAID continued to use a PPI after NSAID cessation. For LDASA users, the percentage of inappropriate PPI continuation was $5.0 \%$. Inappropriate PPI continuation was highest in former NSAID users aged 80 years and older $(16.4 \%)$ and lowest in patients aged between 50 and 59 years (9.9\%). In LDASA users, inappropriate PPI continuation was highest for patients between aged $70-79$ years $(5.3 \%)$ and lowest in the 50-59 years and 60-69 years categories (4.7\% for each category).

\subsection{Cost-Utility Analysis}

For the base case, the strategy of discontinuing PPI cotreatment, as compared to the strategy of PPI continuation, resulted in incremental costs of $€ 170$ (95\% confidence interval -282 to -75 ) indicating savings, and incremental effects gains of 0.003 (95\% confidence interval 0.001-0.005). Stopping PPI co-treatment was a cost-saving strategy for all age categories compared with the strategy of continuation after NSAID or LDASA cessation, and as such inappropriate PPI use (Table 2). Consequently the PPI discontinuation strategy 'dominated' its alternative in

Table 1 Extent of inappropriate PPI use, started as a protective co-medication to NSAID or LDASA treatment and continued despite cessation of these drugs

\begin{tabular}{|c|c|c|c|c|}
\hline \multirow{2}{*}{$\begin{array}{l}\text { Age } \\
\text { categories } \\
\text { (years) }\end{array}$} & \multicolumn{2}{|l|}{ NSAID } & \multicolumn{2}{|l|}{ LDASA } \\
\hline & $\begin{array}{l}\text { First PPI dispensing }{ }^{\mathrm{a}} \text { in combi- } \\
\text { nation with NSAID treatment }{ }^{\mathrm{b}} \text {, } \\
\text { number of subjects }\end{array}$ & $\begin{array}{l}\text { Consecutive PPI dispensing } \\
\text { without NSAID treatment }{ }^{\mathrm{b}}, \\
\text { number of suspects ( } \% \text { from } \\
\text { first PPI dispensing in combi- } \\
\text { nation with NSAID treatment) }\end{array}$ & $\begin{array}{l}\text { First PPI dispensing }{ }^{\mathrm{a}} \text { in } \\
\text { combination with LDASA } \\
\text { treatment }^{\mathrm{b}}, \text { number of subjects }\end{array}$ & $\begin{array}{l}\text { Consecutive PPI dispensing } \\
\text { without LDASA treatment }{ }^{\mathrm{b}} \text {, } \\
\text { number of suspects ( } \% \text { from first } \\
\text { PPI dispensing in combination } \\
\text { with LDASA treatment) }\end{array}$ \\
\hline $51-60$ & 83,354 & 8236 (9.9) & 24,938 & $1166(4.7)$ \\
\hline $61-70$ & 83,750 & $8446(10.1)$ & 45,201 & $2145(4.7)$ \\
\hline $71-80$ & 57,998 & 6796 (11.7) & 50,761 & $2698(5.3)$ \\
\hline$>80$ & 22,357 & 3674 (16.4) & 52,952 & $2623(5.0)$ \\
\hline Total & 247,460 & $27,152(11.0)$ & 173,852 & $8632(5.0)$ \\
\hline
\end{tabular}

Data were available from 1756 Dutch community pharmacies. Results presented here were extrapolated to the total number of 1979 community pharmacies in the Netherlands in 2014

LDASA low-dose acetylsalicylic acid, NSAID non-steroidal anti-inflammatory drug, PPI proton pump inhibitor

${ }^{a} \mathrm{~A}$ first PPI dispensing was a dispensing without any prior PPI dispensing within the preceding 12 months

${ }^{\mathrm{b}}$ Combination with NSAID (or LDASA) treatment was a dispensing within 10 days of NSAID (or LDASA) treatment prior or posterior to the PPI dispensing 
Table 2 Costs, QALYs and ICERs of PPI discontinuation after cessation of NSAID or LDASA treatment as compared to inappropriate PPI continuation

\begin{tabular}{|c|c|c|c|c|c|c|c|c|}
\hline $\begin{array}{l}\text { Age } \\
\text { category, } \\
\text { years }\end{array}$ & $\begin{array}{l}\text { Costs for } \\
\text { stopping PPI } \\
(€)\end{array}$ & $\begin{array}{l}\text { Costs for PPI } \\
\text { continuation } \\
(€)\end{array}$ & Incremental costs $(€)$ & QALYs no PPI & QALYs PPI & $\begin{array}{l}\text { Incremen- } \\
\text { tal QALYs }\end{array}$ & $\operatorname{ICER}(€)$ & $95 \% \mathrm{CI}$ \\
\hline $51-60$ & 195.39 & 274.51 & -79.12 & 4767 & 4767 & 0.000 & 'Dominates' & $\begin{array}{l}\text { 'Dominates' to } \\
\text { 'Dominates' }\end{array}$ \\
\hline $61-70$ & 208.45 & 290.30 & -81.85 & 4713 & 4713 & 0.000 & 'Dominates' & $\begin{array}{l}\text { 'Dominates' to } \\
\text { 'Dominates' }\end{array}$ \\
\hline $71-80$ & 503.19 & 673.65 & -170.46 & 4564 & 4562 & 0.003 & 'Dominates' & $\begin{array}{l}\text { 'Dominates' to } \\
\text { 'Dominates' }\end{array}$ \\
\hline$>80$ & $1,841.41$ & $2,394.57$ & -553.16 & 4067 & 4051 & 0.016 & 'Dominates' & $\begin{array}{l}\text { 'Dominates' to } \\
\text { 'Dominates' }\end{array}$ \\
\hline
\end{tabular}

CI confidence interval, ICER incremental cost-effectiveness ratio, LDASA low-dose acetylsalicylic acid, NSAID non-steroidal anti-inflammatory drug, $P P I$ proton pump inhibitor, $Q A L Y$ quality-adjusted life-year

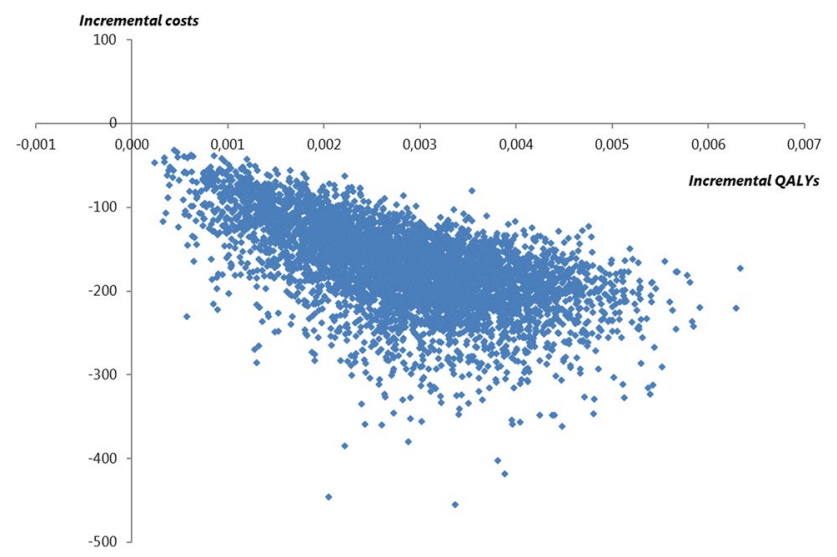

Fig. 2 Incremental costs and quality-adjusted life-years (QALYs) for stopping inappropriate proton pump inhibitor (PPI) continuation after cessation of the related non-steroidal anti-inflammatory drug (NSAID) or low-dose acetylsalicylic acid (LDASA) co-medication for the base case

all 5000 simulations (Fig. 2). This was due to both costs saved for the medication and for the treatment of adverse effects (negative incremental costs) and the gain of QALYs because of a lower incidence of adverse effects resulting from continued PPI use (positive incremental QALYs). In older age categories, the difference between costs and effects for the two strategies increased, implicating that the cost effectiveness of interventions to stop inappropriate PPI use increases with a patients' age.

\subsection{Budget Impact Analysis}

The results of the BIA are shown in Table 3. The total budget impact of conducting interventions to discontinue inappropriate PPI use after cessation of NSAID or LDASA treatment was almost $€ 1,050,000$. Based on the total budget impact of a $100 \%$ successful intervention, this equals $€ 29$ per patient.

\section{Discussion}

In 2014, a substantial number of patients in the Netherlands who had been prescribed an NSAID or LDASA in combination with a PPI to prevent GI adverse effects were found to have inappropriately continued their PPI use after cessation of NSAID or LDASA treatment. The highest percentage (16.4\%) of patients inappropriately using a PPI was found

Table 3 Budget impact after 1 year to stop inappropriate PPI use after the cessation of NSAIDs or LDASA

\begin{tabular}{lccc}
\hline Age categories, years & $\begin{array}{l}\text { Total number of consecutive PPI dispensing without } \\
\text { NSAID or LDASA treatment }\end{array}$ & $\begin{array}{l}\text { Costs per patient per year of stopping } \\
\text { PPI }(€)\end{array}$ & $\begin{array}{l}\text { Total budget } \\
\text { impact }(€)\end{array}$ \\
\hline $51-60$ & 9402 & 57.78 & 543,248 \\
$61-70$ & 10,591 & 57.78 & 611,948 \\
$71-80$ & 9494 & 34.98 & 332,100 \\
$>80$ & 6297 & -69.49 & $-437,579$ \\
Total & 35,784 & & $1,049,717$ \\
\hline
\end{tabular}

LDASA low-dose acetylsalicylic acid, NSAIDs non-steroidal anti-inflammatory drugs, PPI proton pump inhibitor 
in the oldest age category ( $>80$ years) after NSAID discontinuation. Our analysis showed that discontinuation of inappropriate PPI use resulted in substantial cost savings and improvement of quality of life. From the costs' perspective, this was to be expected because of the savings of the direct medication costs for the PPIs. Additional gains in QALYs and cost savings were achieved by preventing hip fractures and CAP as PPI adverse effects.

Earlier studies reported substantially higher percentages of inappropriate PPI use. In a recent US study, about $80 \%$ of PPI continuation was found to be inappropriate because of the absence of a valid indication after hospital discharge [29]. An Australian study showed that 63\% of all PPI prescriptions were not based on actual guideline recommendations [30]. An Irish study considered 33\% of PPI use as inappropriate [31]. The considerable lower percentages found in the present study might be explained by the fact that our study focused on PPI use as a co-medication to NSAID or LDASA treatment. Thus, inappropriate PPI use due to other reasons such as PPI continuation after hospital discharge was not taken into account. A more reticent prescribing attitude in the Netherlands may also have contributed to the lower percentages of inappropriate PPI use observed in our study. Finally, the quality of prescribing, and dispensing, may be higher in the Netherlands as has been described previously for other aspects of inappropriate prescribing [47].

Except as a co-medication in patients using an NSAID or LDASA, PPIs could also have been prescribed for other reasons such as Zollinger-Ellison syndrome, Barret's esophagus or esophagitis. A limitation of dispensing data used in the present study is that they did not provide information on these disorders. However, as their prevalence is low, patients with these disorders were unlikely to have substantially influenced our results. Furthermore, we have only included patients who started PPI treatment and who had not been dispensed a PPI in the prior 12 months. These patients also had to have a period of NSAID or LDASA use within a narrow time window of 10 days around the PPI treatment initiation. Thus, patients included were most likely to use PPIs as a protective co-medication.

According to the guidelines, PPI use should be periodically evaluated to prevent long-term use and the development of rebound effects on gastric acid production. As the result of strict inclusion criteria, inappropriate PPI continuation might have been missed and our findings therefore may be too conservative. In addition, we only included costs and QALYs for hip fractures but not for other fractures that might occur as PPI side effects. This could also make our estimates for the consequences of PPI adverse effects too conservative. Finally, drug prices used in the BIA are only an indication for the real prices paid by the health insurers.

Nevertheless, unlike list prices, they are probably the best indication of the actual prices in the Netherlands, which as such are not transparent because of direct price negotiations between manufacturers on the one hand, and health insurers or hospitals on the other hand. A strength of this study is that we used the data of nearly $90 \%$ of all Dutch community pharmacies. Our results therefore are representative of the Netherlands. Because our information was extracted from routinely collected dispensing data, reporting bias is also unlikely. In our model, we assumed that event rates were constant, whereas this is likely to change over time. However, because to our knowledge there are no data available on the rates over time, under the current conditions the assumptions are the best available.

The BIA showed that an intervention to discontinue inappropriate PPI use related to previous NSAID or LDASA treatment would cost up to $€ 29$ extra per patient. These costs are determined by the costs already invested for an intervention to stop inappropriate PPI use, minus the savings resulting from the prevention of PPI-induced adverse effects and their detrimental consequences. The cost-utility analysis shows that this intervention will easily pay for itself in the following years (as indicated by the negative incremental costs). Pharmacists in cooperation with general practitioners could effectively intervene by means of adequate patient counselling or increasing awareness, for instance by a letter, to stop the inappropriate use of PPI [48].

In a study in outpatient clinics of Australian hospitals, a strategy to reduce the inappropriate use of PPI by more intensive patient counselling proved effective [37, 49]. Based on our results, in Dutch community pharmacies, by monthly searches of dispensing data, 18 potentially inappropriate PPI users per pharmacy on average can be easily identified. Subsequently, in consultation with the general practitioners and in the absence of other reasons for PPI discontinuation, these patients could be labelled for not dispensing further PPIs. With regard to the BIA, it is important to note that the prices used to calculate the BIA more or less reflected the actual prices used by the healthcare insurers.

In the Netherlands, the prices of generic medicines are very low as the result of the legal power of health insurers to impose price-restricting measures. For a given drug, these prices may differ between insurers while the basis for pricing is not transparent. We believe that under these conditions the prices used in the present study are the best available. As the risks of adverse effects increases with older age, discontinuation of inappropriate PPI use proved more cost effective in older patients.

\section{Conclusions}

The results of our study show that a substantial number of patients inappropriately continue to use a PPI after cessation of NSAID or LDASA treatment. Because adverse effects and 
their detrimental consequences are avoided, interventions to stop inappropriate PPI use, particularly in older patients, are likely to pay for themselves. Therefore, their routine use should be promoted.

\section{Compliance with Ethical Standards}

Funding An unrestricted grant was received from the Royal Dutch Pharmacists Association (KNMP), The Hague, the Netherlands.

Conflict of interest Martina Teichert is an employee of KNMP. However, the funding body had no role in the analysis nor interpretation of the findings of this article. Sek Hung Chau, Reinier L. Sluiter, Jacqueline G. Hugtenburg, Michel Wensing and Wietske Kievit have no conflicts of interest that are directly relevant to the content of this article.

Ethics approval This study, using computer simulations (Markov model) and anonymised medication dispensing data, does not contain any studies with human participants or animals performed by any of the authors. Therefore, it did not require ethics approval according to current Dutch legislation.

Open Access This article is distributed under the terms of the Creative Commons Attribution-NonCommercial 4.0 International License (http://creativecommons.org/licenses/by-nc/4.0/), which permits any noncommercial use, distribution, and reproduction in any medium, provided you give appropriate credit to the original author(s) and the source, provide a link to the Creative Commons license, and indicate if changes were made.

\section{References}

1. Garcia EB, Michaud K, Wolfe F. Gastrointestinal prophylactic therapy among patients with arthritis treated by rheumatology specialists. J Rheumatol. 2006;33(4):779-84.

2. García Rodríguez LA, Lin KJ, Hernández-Díaz S, Johansson S. Risk of upper gastrointestinal bleeding with low-dose acetylsalicylic acid alone and in combination with clopidogrel and other medications. Circulation. 2011;123(10):1108-15.

3. van der Hooft CS, Sturkenboom MCJM, van Grootheest K, Kingma HJ, Stricker B. Adverse drug reaction-related hospitalisations: a nationwide study in the Netherlands. Drug Saf. 2006;29(2):161-8.

4. Leendertse AJ, Egberts AC, Stoker LJ, van den Bemt PM. Frequency of and risk factors for preventable medication-related hospital admissions in the Netherlands. Arch Intern Med. 2008; $17: 1890-6$

5. Lanza F, Chan F, Quigley E, Practice Parameters Committee of the American College of Gastroenterology. Guidelines for prevention of NSAID-related ulcer complications. Am J Gastroenterol. 2009;104(3):728-38.

6. Scheiman JM, Hindley CE. Strategies to optimize treatment with NSAIDs in patients at risk for gastrointestinal and cardiovascular adverse events. Clin Ther. 2010;32(4):667-77.

7. Bhatt D, Scheiman J, Abraham N, Antman E, Chan F, Furberg C, et al. ACCF/ACG/AHA 2008 expert consensus document on reducing the gastrointestinal risks of antiplatelet therapy and NSAID use: a report of the American College of Cardiology Foundation Task Force on Clinical Expert Consensus Documents. Circulation. 2008;118:1894-909.
8. Kwaliteitsinstituut voor de Gezondheidszorg (CBO). Richtlijn NSAID-gebruik en preventie van maagschade [Guideline NSAIDuse and the prevention of gastro-intestinal damage]. Alphen aan den Rijn: Van Zuiden Communications; 2003.

9. Warlé-van Herwaarden MF, Kramers C, Sturkenboom MC, van den Bemt PM, De Smet PA, Dutch HARM-Wrestling Task Force. Targeting outpatient drug safety: recommendations of the Dutch HARM-Wrestling Task Force. Drug Saf. 2012;35(3):245-59. https://doi.org/10.2165/11596000-000000000-00000.

10. Warlé-van Herwaarden MF, Valkhoff VE, Teichert M, Koffeman AR, 't Jong GW, Sturkenboom MCJM, et al. Development and application of indicators for the reduction of potentially preventable hospital admissions related to medications. Expert Opin Drug Saf. 2014;13(2):157-65.

11. Teichert M, Schoenmakers T, Kylstra N, Mosk B, Bouvy ML, van de Vaart F, et al. Quality indicators for pharmaceutical care: a comprehensive set with national scores for Dutch community pharmacies. Int J Clin Pharm. 2016;38(4):870-9. https://doi. org/10.1007/s11096-016-0301-x.

12. Valkhoff VE, Van Soest EM, Sturkenboom MC, Kuipers EJ. Timetrends in gastroprotection with nonsteroidal anti-inflammatory drugs (NSAIDs). Aliment Pharmacol Ther. 2010;3(11):1218-28.

13. Stichting Farmaceutische Kengetallen (Dutch Foundation for Pharmaceutical Statistics). Van Rennie tot PPI [From Rennie to PPI]. Pharm Weekbl. 2014;149(14):13.

14. Stichting Farmaceutische Kengetallen (Dutch Foundation for Pharmaceutical Statistics). De 'gouwe ouwe' doen het nog goed [The 'oldies' are still performing well]. Pharm Weekbl. 2016;151(3):9.

15. Lanas A, Garcia-Rodriguez L, Arroyo M, Bujanda L, Gomollón $\mathrm{F}$, Forné M, et al. Effect of antisecretory drugs and nitrates on the risk of ulcer bleeding associated with nonsteroidal anti-inflammatory drugs, antiplatelet agents, and anticoagulants. Am J Gastroenterol. 2007;102(3):507-15.

16. Ali T, Roberts D, Tierney W. Long-term safety concerns with proton pump inhibitors. Am J Med. 2009;122(10):896-903.

17. Yu EW, Bauer SR, Bain PA, Bauer DC. Proton pump inhibitors and risk of fractures: a meta-analysis of 11 international studies. Am J Med. 2011;124(6):519-26.

18. Yang YX, Lewis JD, Epstein S, Metz DC. Long-term proton pump inhibitor therapy and risk of hip fracture. JAMA. 2006;296(24):2947-53.

19. Ngamruengphong S, Leontiadis GI, Radhi S, Dentino A, Nugent K. Proton pump inhibitors and risk of fracture: a systematic review and meta-analysis of observational studies. Am J Gastroenterol. 2011;106:1209-18.

20. Eom C-S, Lee S-S. Risk of fracture and pneumonia from acid suppressive drugs. World J Methodol. 2011;1(1):15-21.

21. Panday K, Gona A, Humphrey M. Medication-induced osteoporosis: screening and treatment strategies. Ther Adv Musculoskelet Dis. 2014;5:185-202.

22. Gulmez S, Holm A, Frederiksen H, Jensen T, Pedersen C, Hallas J. Use of proton pump inhibitors and the risk of communityacquired pneumonia: a population-based case-control study. Arch Intern Med. 2007;167(9):950-5.

23. Eurich D, Sadowski C, Simpson S, Marrie T, Majumdar S. Recurrent community-acquired pneumonia in patients starting acidsuppressing drugs. Am J Med. 2010;123(1):47-53.

24. Sarkar M, Hennessy S, Yang XY. Proton-pump inhibitor use and the risk for community-acquired pneumonia. Ann Intern Med. 2008;149:391-8.

25. Laheij R, Sturkenboom MCJM, Haassing R-J, Dieleman J, Stricker B, Jansen J. Risk of community-acquired pneumonia and use of gastric acid suppressive drugs. JAMA. 2004;292(16):1955-60. 
26. Heidelbaugh J, Kim A, Chang R, Walker P. Overutilization of proton-pump inhibitors: what the clinician needs to know. Ther Adv Gastroenterol. 2012;5(4):219-32.

27. Batuwitage B, Kingham J, Morgan N, Bartlett R. Inappropriate prescribing of proton pump inhibitors in primary care. Postgrad Med J. 2007;83:66-8. https://doi.org/10.1136/pgmj.2006.051151.

28. Grant K, Al-Adhami N, Tordoff J, Livesey J, Barbezat E, Reith D. Continuation of proton pump inhibitors from hospital to community. Pharm World Sci. 2006;28(4):189-93.

29. Leri F, Ayzenberg M, Voyce SJ, Klein K, Hartz L, Smego RA. Four-year trends of inappropriate proton pump inhibitor use after hospital discharge. South Med J. 2013;106(4):270-3.

30. Naunton M, Peterson GM, Bleasel MD. Overuse of proton pump inhibitors. J Clin Pharm Ther. 2000;25:333-40.

31. Mat Saad AZ, Collins N, Lobo MM, O'Connor HJ. Proton pump inhibitors: a survey of prescribing in an Irish general hospital. Int J Clin Pract. 2005;59(1):31-4. https://doi.org/10.111 1/j.1742-1241.2004.00298.x.

32. de Groot N, Spiegel B, van Haalen H, de Wit N, Siersema P, van Oijen M. Gastroprotective strategies in chronic NSAID users: a cost-effectiveness analysis comparing single-tablet formulations with individual components. Value Health. 2013;16(5):769-77.

33. de Groot N, van Haalen H, Spiegel B, Laine L, Lanas A, Focks $\mathrm{J}$, et al. Gastroprotection in low-dose aspirin users for primary and secondary prevention of ACS: results of a cost-effectiveness analysis including compliance. Cardiovasc Drugs Ther. 2013;27(4):341-57.

34. Sluiter R, Chau S, Kievit W, Teichert M, Hugtenburg J. Costeffectiveness of proton pump inhibitor initiation aimed to prevent upper gastrointestinal toxicity in patients using low-dose acetylsalicylic acid. Value Health. 2015;18(7):648.

35. Stichting Farmaceutische Kengetallen (Dutch Foundation for Pharmaceutical Statistics). Data en feiten 2015: het jaar 2014 in cijfers [Data and facts 2015: the year 2014 in numbers]. Stichting Farmaceutische Kengetallen; 2015.

36. World Health Organization Collaborating Centre for Drug Statistics Methodology. Guidelines for ATC classification and DDD assignment. Oslo; 2004.

37. Numans ME, De Wit NJ, Dirven JAM, Heemstra-Borst CG, Hurenkamp GJB, Scheele ME, et al. NHG-Standaard Maagklachten (tweede herziening) [Dutch College of General Practitioners' (NHG) practice guideline "Gastric symptoms" (second revision)]. Huisarts Wet. 2013;56:23-35.

38. Drummond MF. Methods for the economic evaluation of health care programmes. Oxford medical publications. 3rd ed. Oxford: Oxford University Press; 2005.
39. Briggs AH, Claxton K, Sculpher MJ. Decision modelling for health economic evaluation. Oxford handbooks in health economic evaluation. Oxford: Oxford University Press; 2006.

40. Spoorenberg SM, Bos WJ, Heijligenberg R, Voorn PG, Grutters JC, Rijkers GT, et al. Microbial aetiology, outcomes, and costs of hospitalisation for community-acquired pneumonia; an observational analysis. BMC Infect Dis. 2014;14:335.

41. Letsel Informatie Systeem 2012 [Injury Information System 2012]. http://veiligheid.nl. Accessed 6 Sep 2019.

42. Centraal Bureau voor de Statistiek [Dutch Statistics]. Consumentenprijzen [Consumer prices]. http://statline.cbs.nl/. Accessed 5 Jul 2014.

43. Peasgood T, Herrmann K, Kanis JA, Brazier JE. An updated systematic review of health state utility values for osteoporosis related conditions. Osteoporos Int. 2009;20(6):853-68.

44. Zorginstituut Nederland [National Health Care Institute]. Richtlijnen voor het uitvoeren van economische evaluaties in de gezondheidszorg. [Guidelines for performing economical evaluations in health care]; 2015.

45. Goldstein JL, Howard KB, Walton SM, McLaughlin TP, Kruzikas DT. Impact of adherence to concomitant gastroprotective therapy on nonsteroidal-related gastroduodenal ulcer complications. Clin Gastroenterol Hepatol. 2006;4(11):1337-45.

46. Mauskopf JA, Sullivan SD, Annemans L, Caro J, Mullins CD, Nuijten M, et al. Principles of good practice for budget impact analysis: report of the ISPOR Task Force on good research practices-budget impact analysis. Value Health. 2007;10:336-47.

47. Teichert M, Schermer T, van den Nieuwenhof L, De Smet PA, Wensing M. Prevalence of inappropriate prescribing of inhaled corticosteroids for respiratory tract infections in the Netherlands: a retrospective cohort study. NPJ Prim Care Respir Med. 2014;16(24):14086. https://doi.org/10.1038/npjpcrm.2014.86.

48. Krol N, Wensing M, Haaijer-Ruskamp F, Muris JW, Numans ME, Schattenberg G, et al. Patient-directed strategy to reduce prescribing for patients with dyspepsia in general practice: a randomized trial. Aliment Pharmacol Ther. 2004;19(8):917-22. https://doi.org /10.1111/j.1365-2036.2004.01928.x.

49. Reeve E, Andrews J, Wiese M, Hendrix I, Roberts M, Shakib S. Feasibility of a patient-centered deprescribing process to reduce inappropriate use of proton pump inhibitors. Ann Pharmacother. 2015;49(1):29-38.

\section{Affiliations}

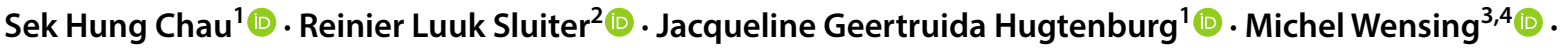 Wietske Kievit $^{2}$ (1) . Martina Teichert ${ }^{5}$ (1)}

1 Department of Clinical Pharmacology and Pharmacy, Amsterdam Public Health Research Institute, Amsterdam UMC, Vrije Universiteit Amsterdam, De Boelelaan 1117, Amsterdam, The Netherlands

2 Department for Health Evidence, Radboud University Medical Center, Geert Grooteplein 21, Nijmegen, The Netherlands

3 Radboud University Medical Center, Scientific Institute for Quality of Healthcare (IQ Healthcare), Geert Grooteplein 21, Nijmegen, The Netherlands
4 Department of General Practice and Health Services Research, Heidelberg University, Im Neuenheimer Feld 130.3, Heidelberg, Germany

5 Department of Clinical Pharmacy and Toxicology, Leiden University Medical Center, Albinusdreef 2, Leiden, The Netherlands 